This is a post-print version of the following article: Rovira-Esteva, Sara; Orero, Pilar; Franco, Javier. (2015). Bibliometric and bibliographical research in

Translation Studies. Perspectives: Studies in Translatology, 23(2). Doi:

http://dx.doi.org/10.1080/0907676X.2015.1026361

\title{
INTRODUCTION
}

\section{Bibliometric and Bibliographical Research in Translation Studies}

Sara Rovira-Esteva (a), Pilar Orero (a) \& Javier Franco Aixelá (b)

a Departament de Traducció i d'Interpretació i d'Estudis de l'Àsia Oriental, Universitat Autònoma de

Barcelona, Bellaterra, Spain

b Departamento de Traducción e Interpretación, Universidad de Alicante, Alicante, Spain

Sink or swim, publish or perish, there seems to be no way to live and let live, as Cole Porter sang. We live plumb in the middle of a system, created by economists, where accountability is the name of the game. All our working hours have to be tagged under given labels, which are evaluated through random benchmarking by seemingly aseptic, objective parameters. Our work outcome must be also accountable both quantitative and qualitatively to fit to pre-established thresholds of productivity, originality, innovation, etc.

While we all know that attitudes towards performance in work, or life, are varied leading to unbalanced responsibilities and job share, we also know that kosher ledgering is not the answer. Having said this, it is true that some system to record work performance is needed, and in higher education institutions the quest for measuring has shifted drastically in the last decade. Teaching outcome is measured by student satisfaction, admin dedication is measured by time spent in the post, research is measured by publications, their quality and their impact - and both concepts get systematically mixed. Indexed journal articles are the new research currency giving indicators for a myriad of purposes, from securing tenure to supervising PhDs to fund raising for departments.

At present, and the number is growing to meet demand, there are over 110 living specialized journals in Translation Studies (TS) throughout the world, be they online or in paper format. There are quite a few dictionaries and encyclopedias dealing only with our interdiscipline. The number of scientific publications (books, chapters in edited books, journal articles, $\mathrm{PhD}$ 's...) in our field clearly exceeds 60,000 items, with over 40,000 issued in the last twenty years. Paradoxically, although journal articles and book chapters amount to almost the same number within TS (about $40 \%$ each, with a supplementary $15 \%$ of books), and although it is increasingly clear that TS scholars cite books more than anything else, any research outcome which is not a journal article runs the risk of becoming invisible.

This publication fever has also a silver lining: the vast quantity of research items available for mapping the field from a bottom-up perspective. The number of publications on any of the "big issues" runs into the thousands, and perhaps time has come to start to make quantitative observations gauging what the (much work the) TS community has been doing in these last 20-30 years, and to establish an informed state (or states) of the art. TS as any other established academic discipline has now enough critical mass to lend itself to analysis from a bibliometric perspective. And it is high time to do so, after the dramatic boom in specialized research starting in the 1990 s we have just described. 
This Special issue of Perspectives will look at a varied assortment of bibliographic and bibliometric issues, from overviews of research in non-professional interpreting to critical views of the way research is valued. Basically, we could speak of two great approaches that could be termed as metabibliometric and bibliometric proper.

The metabibliometric approach attempts to understand the ways we collect, identify, classify, disseminate and measure academic production, both within our discipline and from the outside. Articles such as Gile's, Franco and Rovira's, or Zanettin, Saldanha and Harding's examine crucial methodological issues, such as the way innocent-looking collection of bibliographic data might impose particular mappings of TS or how "objective" measuring of impact and the need to obtain high impact scores might marginalize local concerns or local languages.

The bibliometric proper approach mainly focuses on providing diachronic or synchronic pictures of the state of the art, based on empirical analyses of sectorial bibliographies or production centers. Thus, Van Doorslaer and Gambier, MartínezGómez, Zhang, Pan, Chen, and Luo, $\mathrm{Xu}$, and $\mathrm{Li}$ approach issues such as the attempt to understand which are the main research interests depending on affiliations, mapping discourse analysis in TS through a survey of several journals, how nonprofessional interpreting has been explained away in the past and is approached now, and what the visibility of Mainland China is within the international TS community. And, by the way, the considerable presence of Chinese researchers in this issue can rightly be taken as a sign of a very important TS power which seems to be awakening in our area, and most likely with new approaches and contributions to make. Welcome to the party in this ever open house.

The intention of this issue is to provide the opportunity to raise awareness to the existence of TS as a bibliographic entity whose maturity merits, nay, needs careful scrutiny in order to know what we are doing and where we are. Thirty years ago, in the 1980 s, it was perfectly possible to be personally privy to almost everything of any substance ever written on translation. In 2015 a scholar in TS cannot ever hope to cope with the more than 3,000 new publications issued each year. We need maps, and we need to know how these maps are drawn in order to be helped instead of unconsciously steered by them. The multiple and complementary perspectives we provide here will hopefully help us to advance in the right direction. Only then will we be really aware of where the field stands, allowing for comparisons with other fields, and perhaps be able to develop a useful tool to demand similar recognition to our field from other disciplines with a longer academic tradition, which seem to enjoy more respect and, hence, more international recogntition. 